\title{
Laboratory experiments on the effects of a gastropod (Hydrobia totteni) on survival of an infaunal deposit-feeding polychaete (Capitella capitata)
}

\author{
Peter S. Petraitis* \\ Biology Department, Woods Hole Oceanographic Institution, Woods Hole, Massachusetts 02543, USA
}

\begin{abstract}
Many species which quickly colonize newly disturbed patches have the potential for rapid reproduction and show broad physiological tolerances. Often these species are uncommon in older patches and it is thought predation and/or competition is the primary cause for their disappearance. As a direct test of the sensitivity of an early colonizer to other species, this study examines the effects of the snail Hydrobia totteni on the early survivorship of the polychaete Capitella capitata (species type I). Family effects (i.e. either maternal effects or genetic differences among females) account for most of the variation in survivorship from free-swimming larvae to $2 \mathrm{wk}$ of age. If family effects are controlled, then survivorship of Capitella is always poorer in the presence of $H$. totteni. There are no detectable density-dependent or time-dependent effects.
\end{abstract}

\section{INTRODUCTION}

The first arrivals after a disturbance, which causes a local mass extinction, are often characterized by a distinctive set of life history traits (Grassle and Sanders, 1973; Grassle and Grassle, 1977). These early arrivals are typically rare in undisturbed habitats but can be quite common for a brief period following a disturbance. The term 'opportunist' has been applied to these 'weedy' species because of their ability to utilize quickly newly opened patches of habitat. The typical opportunistic species has the capacity for a high rate of reproduction and a physiological tolerance to a wide range of abiotic abuses such as pollution, anoxic sediments and rapid changes in salinity and temperature. It is thought as a patch recovers from a disturbance and other species become established, within-patch biotic interactions drive population levels of the opportunists to low levels. Zajac and Whitlatch $(1982 a, b)$ show, however, a variety of physical and biotic interactions external of patch dynamics to have a strong effect.

Opportunistic species are reported to show poor

- Present address: Biology Department, University of Pennsylvania, Philadelphia, Pennsylvania 19104, USA competitive ability for resources (Grassle and Grassle, 1974), high mortality due to predation (Sanders et al., 1980) or to inadvertent destruction through the activities of other species (Levinton and Stewart, 1982), and low recruitment due to inhibition of settlement (Woodin, 1976; Richter and Sarnthien, 1977; Zajac and Whitlach, 1982b). While the mechanisms of interaction are diverse, there is an implied trade-off; a species can either rapidly utilize newly opened habitat or resist the effects of biotic interactions, but cannot do both. For this reason opportunistic species are often viewed as being classic r-selected species. Yet little direct experimental work has been done (see review of Thistle, 1981; references in Levinton and Stewart, 1982) to examine whether or not opportunists are adversely affected by other species.

In order to test this assumption, this study examines the effect of the snail Hydrobia totteni on the early survivorship of the polychaete Capitella capitata (type I species sensu Grassle and Grassle, 1976). $H$. totteni is a common species in undisturbed sediments, while Capitella is often cited as the typical opportunistic species (e.g. Grassle and Sanders, 1973; McCall, 1977; but see Zajac and Whitlatch, 1982a, b). It has been reported that elimination of Hydrobia species results in rapid colonization by capitellid polychaetes 
(Levinton and Stewart, 1982). The assumption is that Hydrobia, through its activity on the sediment surface, either prevents settlement or inadvertently kills newly settled Capitella.

\section{MATERIALS AND METHODS}

A stock culture of Capitella capitata, species I (Grassle and Grassle, 1976) was founded by offspring from 11 females. Founding mothers were collected as juveniles from J. P. Grassle's sea table at the Marine Biological Laboratories, Woods Hole, MA (USA), and identified by electrophoretic markers. Water in the sea table is unfiltered so these juveniles are colonizers from outside. Stock cultures were maintained in four, 10-inch diameter culture dishes at $19^{\circ} \mathrm{C}$ on a $12 \mathrm{~h}$ light/dark cycle. Sediment, which served as a food source, and water were changed weekly. When sediment was changed, worms from each dish were divided into 4 lots and regrouped so that each dish contained about $1 / 4$ th of the worms from each dish.

All the sediment was collected on 23 July 1980 at Wild Harbor, near Station IV (Sanders et al., 1980). A fraction of sediment less than $300 \mu \mathrm{m}$ was saved and frozen in approximately $1000 \mathrm{~cm}^{3}$ lots. Sediment was thawed at least $24 \mathrm{~h}$ before using.

Experiments were run in 4-inch diameter culture bowls. To prepare the bowls, about $20 \mathrm{~cm}^{3}$ of thawed sediment was mixed with a little seawater, covered and left to stand for 24 to $48 \mathrm{~h}$. Filtered, $19^{\circ} \mathrm{C}$ seawater was carefully added in order to minimize suspension of silt. Larvae were introduced $1 \mathrm{~h}$ later. Water was changed once a week. Experimental bowls were kept at the same temperature and on the light/dark regime as stock culture.

Capitella capitata were introduced to experimental bowls as free-swimming larvae. Larvae within a bowl were siblings and were obtained from brooding females which were isolated from the stock culture. Brooding females were checked daily, thus larvae were less than $24 \mathrm{~h}$ old. I attempted to introduce 50 larvae into each bowl, but in some cases I was unable to do this. The range in densities was 31 to 62 bowl $^{-1}$ ( 0.47 to $0.93 \mathrm{~cm}^{-3}$; bowls are approx. $67 \mathrm{~cm}^{2}$ at the bottom). Survivorship at $2 \mathrm{wk}$ was recorded; all data were arcsine transformed for analysis.

Hydrobia totteni were collected at Little Sippewissett Marsh, Falmouth, MA (USA), the day before they were used. I attempted to use snails of uniform size; all were between 2 and $3 \mathrm{~mm}$ in length.

Source of variation in survivorship. Nine of the 11 founding mothers produced broods large enough to analyze the sources of variation in survivorship. Each brood was randomly split into 2 or 3 experimental bowls. Survivorship at $2 \mathrm{wk}$ was analyzed as a Model II nested analysis of variance (Sokal and Rohlf, 1969).

Effect of Hydrobia on 2 wk survivorship. In order to control for the variation due to family, each brood was split and 50 larvae were challenged with Hydrobia while 50 larvae served as a paired control. The treatments were density of Hydrobia $(10,20,40$, or 80 bowl ${ }^{-1}$ ). Three replicates per treatment were used, and data were analyzed as an analysis of covariance.

Effect of arrival time of Hydrobia. This experiment was set up as a balanced, incomplete block design in order to control for family variation yet allow a reasonable number of treatments. Treatment was time of arrival of 20 Hydrobia after introduction of Capitella capitata larvae; arrival times were 0, 2, 4, 6, $8 \mathrm{~d}$ after introduction. A control of no snails (i.e. larvae never challenged) was included. Ten families were treated as blocks. Larvae from each family were split into 3 lots and assigned to 3 treatments. The design is balanced; each treatment contains 5 replicates, each from a different family.

\section{RESULTS}

\section{Source of variation in survivorship}

There is significant variation in survivorship due to differences among mothers (Table 1). Possibly, this variation is due not only to familial variation, but also to $\mathrm{H}_{2} \mathrm{~S}$ content of mud (i.e. how long the mud had been thawed), level of suspended silt and stage of the larvae. As a check, I reanalyzed a subset of data for which I could correct for bowl-to-bowl variation (Table 1). Most of the variance is still due to differences among females.

The overall mean survivorship to $2 \mathrm{wk}$ is $0.74 \pm 0.01$ SE. There is no correlation between survivorship and the initial number of larvae per bowl. After $2 \mathrm{wk}$, survivorship is quite good; of those worms surviving to $2 \mathrm{wk}, 0.99 \pm 0.01$ live to $3 \mathrm{wk}$ and $0.97 \pm 0.01$ live to $6 \mathrm{wk}$. There is not a significant correlation between 0 to 2 and 2 to $3 \mathrm{wk}$ survivorship.

\section{Effect of Hydrobia on 2 wk survivorship}

I found no overall significant effect of different $\mathrm{Hy}$ drobia densities on 0 to $2 \mathrm{wk}$ survivorship in Capitella capitata (Table 2). The regression of the covariate is significant and thus some of the variation among replicates is due to family effects. While there are no significant effects when comparing among Hydrobia densities, the presence of Hydrobia clearly decreases the survivorship of C. capitata (Fig. 1). In all but 2 
Table 1. Two week survivorship among families derived from founding mothers. Numbers in parentheses: number of larvae initially introduced into a bowl. Full data set analysis uses all the data; subset analysis is a nested ANOVA of families c, d, $\mathrm{f}, \mathrm{g}$, $\mathrm{h}$ and i. Families joined by a common underlining were started on the same day. Variation among day indicates bowl-to-bowl variation since all bowls within a day were set up in the same manner and used randomly

\begin{tabular}{|c|c|c|c|c|c|c|c|c|c|}
\hline a & b & c & d & e & f & g & & $\mathrm{h}$ & i \\
\hline $0.98(50)$ & $0.40(50)$ & $0.82(50)$ & $0.38(52)$ & $0.82(62)$ & $0.30(50)$ & $1.00(54)$ & & $0.74(50)$ & $0.88(50)$ \\
\hline $0.90(50)$ & $0.00(47)$ & $0.78(50)$ & $0.46(54)$ & $0.74(50)$ & $0.43(40)$ & $0.86(50)$ & & $0.62(45)$ & $0.93(42)$ \\
\hline $1.00(49)$ & & & $0.87(31)$ & & & & & & \\
\hline \multicolumn{4}{|c|}{ Source of variation } & df & MS & \multicolumn{3}{|c|}{$\mathrm{F}$} & \\
\hline \multicolumn{10}{|c|}{ Full data set } \\
\hline amo & g females & & & 8 & 876.33 & \multirow{2}{*}{\multicolumn{3}{|c|}{5.28}} & $P<0.01$ \\
\hline with & n families ( & & & 11 & 165.68 & & & & \\
\hline \multicolumn{10}{|l|}{ Subset } \\
\hline \multirow{2}{*}{\multicolumn{4}{|c|}{$\begin{array}{l}\text { among days } \\
\text { among families within days }\end{array}$}} & 2 & 83.87 & \multicolumn{3}{|c|}{0.11} & \\
\hline & & & 3 & 750.94 & \multirow{2}{*}{\multicolumn{3}{|c|}{6.06}} & $\mathrm{P}<0.05$ \\
\hline with & n families & & & 7 & 123.85 & & & & \\
\hline
\end{tabular}

Table 2. Analysis of 2 wk survivorship of Capitella capitata under differing densities of Hydrobia totteni. Broods from single female were split and half served as covariate. Covariate bowls received no $H$. totteni and data are analyzed as analysis of covariance. Covariate data are regrouped by days on which bowls were started and analyzed as ANOVA. See Figure 1 for data

\begin{tabular}{|c|c|c|c|c|}
\hline Source of variation & df & MS & $\mathrm{F}$ & \\
\hline \multicolumn{5}{|l|}{ Analysis of covariance } \\
\hline among densities (adjusted means) & 3 & 190.96 & 1.25 & n.s. \\
\hline regression of covariate & 1 & 1482.61 & 9.66 & $\mathrm{P}<0.05$ \\
\hline error & 7 & 153.43 & & \\
\hline \multicolumn{5}{|l|}{ Analysis of variance } \\
\hline among days & 3 & 627.07 & 3.87 & n.s. \\
\hline error & 7 & 161.85 & & \\
\hline
\end{tabular}

Table 3. Effect of timing of Hydrobia totteni arrival on 2 wk survivorship of Capitella capitata. Design is an incomplete, balanced block and analyzed by procedure given in Mendenhall (1968). N: 'never', i. e. no snails were introduced. A through J: offspring of the 10 mothers. Number preceding the letter is number of larvae introduced

\begin{tabular}{|c|c|c|c|c|c|c|}
\hline \multicolumn{7}{|c|}{ Number of days for which Hydrobia totteni arrival is delayed } \\
\hline 0 & 2 & 4 & 6 & 8 & \multicolumn{2}{|c|}{$\mathrm{N}$} \\
\hline $0.58(45 \mathrm{~A})$ & $0.67(46 \mathrm{~A})$ & $0.84(50 \mathrm{E})$ & $0.50(50 \mathrm{C})$ & $0.50(46 \mathrm{~A})$ & \multicolumn{2}{|c|}{$0.84(50 \mathrm{~B})$} \\
\hline $0.84(50 \mathrm{~B})$ & $0.90(50 \mathrm{~B})$ & $0.94(50 \mathrm{~F})$ & $0.72(46 \mathrm{D})$ & $0.58(50 \mathrm{C})$ & \multicolumn{2}{|c|}{0.77 (39D) } \\
\hline $0.57(47 C)$ & 0.59 (46D) & $0.63(40 G)$ & $0.84(50 \mathrm{E})$ & $0.88(50 \mathrm{~F})$ & \multicolumn{2}{|c|}{$0.78(40 \mathrm{G})$} \\
\hline $1.00(50 \mathrm{I})$ & $0.86(50 \mathrm{E})$ & $1.00(50 \mathrm{I})$ & $0.56(50 \mathrm{H})$ & $0.58(40 \mathrm{G})$ & \multicolumn{2}{|c|}{$0.70(50 \mathrm{H})$} \\
\hline $0.84(50 \mathrm{~J})$ & $0.96(50 \mathrm{~F})$ & $0.82(50 \mathrm{~J})$ & $0.96(50 \mathrm{~J})$ & $0.70(50 \mathrm{H})$ & \multicolumn{2}{|c|}{$0.94(50 \mathrm{I})$} \\
\hline \multicolumn{2}{|c|}{ Source of variation } & df & SS & MS & \multicolumn{2}{|l|}{$\mathrm{F}$} \\
\hline \multicolumn{2}{|c|}{ Among unadjusted treatments } & 5 & 49.14 & - & \multirow{3}{*}{4.47} & \multirow{3}{*}{$\mathrm{P}<0.01$} \\
\hline \multicolumn{2}{|c|}{ Among adjusted blocks } & 9 & 3242.24 & 360.25 & & \\
\hline \multicolumn{2}{|c|}{ Intrablock error } & 15 & 1208.36 & 80.56 & & \\
\hline \multirow{2}{*}{\multicolumn{2}{|c|}{$\begin{array}{l}\text { Among adjusted treatments } \\
\text { Effective error }\end{array}$}} & 5 & 123.71 & 27.74 & \multirow[t]{2}{*}{0.29} & \multirow[t]{2}{*}{ n.s. } \\
\hline & & 15 & & 95.78 & & \\
\hline
\end{tabular}

pairs, survivorship is poorer in the presence of $\mathrm{Hy}$ drobia. Siblings from the same brood but raised without Hydrobia (i.e. the covariate bowl) show, on the average, a $34 \%$ gain in survivorship. A Wilcoxon's signed ranks test of control versus treatment, regardless of Hydrobia density, is significant (Fig. 1). To check for bowl-to-bowl variation, the covariate data were regrouped according to the day on which bowls 


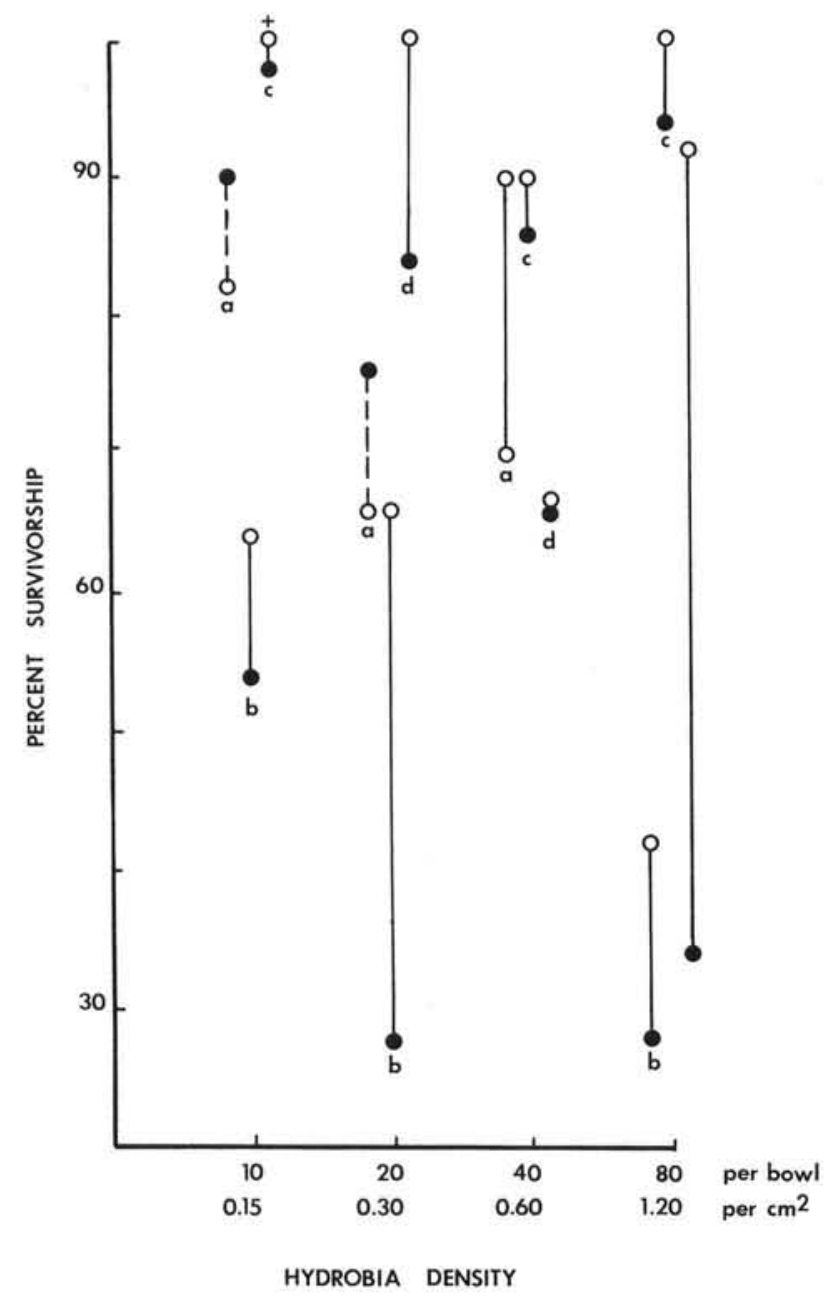

Fig. 1. Two week survivorship of Capitella capitata with and without Hydrobia totteni present; 50 larvae were introduced into each bowl, except a pair which received 46 each and is denoted by a plus. Bowls started on the same day are denoted by the same letter. Closed circles: survivorship in presence of $H$. totteni; open circles, in its absence. Solid and dotted lines connect offspring from same mother; dotted lines: cases where survivorship is better in the presence of $H$. totteni. Wilcoxon's signed-ranks test of all data and ignoring treatment differences gives $\mathrm{P}=0.0212$ under the most conservative assumptions (i.e. the equal survivorship in the ' 40 ' treatment is counted with the cases of better survivorship in the presence of $H$. totteni, and the one case of better survivorship

- which has a tied ranking - is given the higher rank)

were started (see Fig. 1 for data). While $51 \%$ of the variation is due to differences among days, there is not a significant effect of days (Table 2).

\section{Effect of arrival time of Hydrobia}

The timing of Hydrobia arrival has no effect on Capitella capitata survivorship when survivorship is adjusted for block effects (Table 3 ). The standard error of the difference between any 2 treatment means, adjusted for block effects, is .057 ; note that the mean for the $8 \mathrm{~d}$ delay treatment is the only mean which is even 1 standard error from any other.

Families of Capitella are the blocks. These blocks are incomplete since only 3 of the 6 treatments are represented in each block. When adjusted for treatment effects, the blocks show significant variation. Survivorship of Capitella varies among families, and this variation is attributable to maternal effects and/or genetic differences among families.

\section{DISCUSSION}

There is no evidence for a density-dependent or time-dependent effect of Hydrobia on early survivorship of Capitella capitata. If family effects are controlled, there is a presence versus absence effect. As an internal check for consistency among experiments, I performed 2 tests (Table 4). Both tests show no significant differences among experiments when the same treatments are compared. I infer from these tests that any differences among experiments are not due to genetic changes in the stock cultures.

The differences among families seen in Tables 1, 2, and 3 could be due to bowl-to-bowl variation rather than genetic differences among families. It is possible that groups of bowls which were set up on different days could be the source of this variation. Since offspring from a single female are split up into bowls which were set up on the same day, block effects could be due to variation among bowls from different days rather than among families. This type of error has been called restriction error (Anderson and McLean, 1974).

Two lines of evidence suggest to me that not all of the variation among families is due to restriction error. First, I cannot show a significant variance component due to variation among days (Table 1 ). Second and

Table 4. Two tests for consistency of results among experiments: (1) Analysis of variance among replicates without Hydrobia totteni present; first replicate from each mother in Table 1, covariates from Fig. 1, and the 'never' bowls from Table 3 are used. (2) Analysis of variance among replicates with $20 \mathrm{H}$. totteni bowl ${ }^{-1}$. ' $20^{\prime}$ treatment bowls from Table 2 and 'zero' treatment bowls from Table 3 are used

\begin{tabular}{|lrrrr|}
\hline \multicolumn{1}{|c}{ Source of variation } & df & MS & F & \\
\hline Test 1: No Hydrobia & & & & \\
Among experiments & 2 & 133.38 & 0.48 & n.s. \\
Error & 23 & 279.04 & & \\
Test 2: 20 Hydrobia & & & & \\
Among experiments & 1 & 261.58 & 0.89 & n.s. \\
Error & 6 & 292.97 & & \\
\hline
\end{tabular}


more persuasive is a re-analysis of Table 1 data using an independent estimate of the restriction error. The treatment mean square from Table 2 (627.07) provides an estimate of the added variance due to bowl variation, i.e. the restriction error. The restriction error variance component is estimated to be 170.58. In Table 1, the mean square for the differences among families contains components due to restriction effects and due to family effects. I recalculated the mean square corrected for restriction, MS $=165.58+(2.21)$ (321.19 - 170.58) $=498.90$ (for calculation of variance components, see Sokal and Rohlf, 1969). The F ratio remains significant; $F=498.90 / 165.68=3.01, \mathrm{P}<0.05$ for d.f. $=8,11$. I infer from this estimated mean square that there are still family effects even when the estimator is corrected for possible restriction effects.

It could be argued that my inability to detect densitydependence is simply a matter of insufficient sample size. Thus even though I can show a presence/absence effect of Hydrobia (Fig. 1), it is possible that other factors such as family effects, inflate the error mean square for most tests. This inflation may be large; analysis of variance shows $67 \%$ of the variation is due to differences among families while the rest (33\%) is due to variation among replicate bowls within families. Even so, when family effects are taken into account the tests are still not significant.

I believe the problem is not simply a matter of sample size since the variation among treatments is the same magnitude as the variation within families. First, the largest difference I find within a family but between density treatments is 0.58 (Fig. 1) while the largest difference within a family under the same treatment is 0.40 (Table 1). Second, if the standard deviation within families is calculated for each family in Table 1 and Fig. 1, and then compared, there is no difference regardless of treatment. For data in Table 1, within families under the same treatment, the mean standard deviation is 8.48 (expressed as arcsin-square root transformed variables). For Fig. 1, within families under different treatments, the mean standard deviation is similar, i.e. 9.00. Mann-Whitney U-test shows these values are not significantly different. Families show as much variation in survivorship under constant conditions as they do among different treatments.

Clearly family effects could play a role in hiding a pattern of density dependence and blurring the effects of Hydrobia density on Capitella capitata survivorship. Yet the degree of blurring would depend on the mechanism by which Hydrobia affects $C$. capitata survivorship. For example, if only very young worms are susceptible to inadvertent burial by Hydrobia, then the effects of Hydrobia could vary as growth rate of $C$. capitata varies. Since C. capitata sp. I growth shows a strong family component (P. S. Petraitis, unpubl.), and a strong diet component (Tenore, 1981), the effects of Hydrobia density could be further confounded by genotype $\mathrm{x}$ environment (i.e. diet) interaction.

When confounded by these interactions, patterns of recruitment and succession in the field may be difficult to detect even when Capitella capitata are identified correctly. Family effects may inflate error estimates so much that extremely large sample sizes would be needed to detect significance. Even when sampling is corrected for family effects, detection of significance still may be difficult. As a way of illustration, I calculated the weighted average mean square for Tables 1 , 2 , and 3 (average $=131.31$ ) and computed the sample size required to detect a $10 \%$ decline in survivorship due to treatment effect. I assumed survivorship in the control to be 0.80 ; this is near the overall average for 2 wk survivorship in C. capitata. In order to be $80 \%$ certain that this level of difference will be detected, 16 replications per treatment are required (Sokal and Rohlf, 1969). It seems likely in field situations, where many factors are not controlled, that the required sample size would have to be even larger.

The studies of Zajac and Whitlatch (1982a, b) clearly show that both initial recolonization and subsequent succession of infaunal communities are highly variable. They stress the importance of various auto- and synecological factors which may account for this variability. The results of this study on Capitella species I suggest that genetic variation may also be a very important consideration.

Acknowledgements. I thank J. P. Grassle for doing the electrophoresis of original females. This research was done while I was a postdoctoral scholar at Woods Hole Oceanographic Institute. I thank Judy and Fred Grassle for their help, comments and support during my stay in Woods Hole. This is Contribution No. 5640 from Woods Hole Oceanographic Institution.

\section{LITERATURE CITED}

Anderson, V. L., McLean, R. A. (1974). Restriction errors: a dimension in teaching experimental statistics. Am. Stat. 28: $145-152$

Grassle, J. F., Grassle, J. P. (1974). Opportunistic life histories and genetic systems in marine benthic polychaetes. J. mar. Res. 32: 253-284

Grassle, J. F., Grassle, J. P. (1977). Temporal adaptations in sibling species of Capitella. In: Coull, B. C. (ed.) Bell Baruch Library in Marine Science, No.6. University of South Carolina, Columbia, S.C., p. 177-189

Grassle, J. F., Sanders, H. L. (1973). Life histories and the role of disturbance. Deep Sea Res. 20: 643-659

Grassle, J. P., Grassle. J. F. (1976). Sibling species in the marine pollution indicator Capitella (Polychaeta). Science, N.Y. 192: 567-569

Levinton, J. S., Stewart, S. (1982). Marine succession: the effect of two deposit-feeding gastropod species on the population growth of Paranais litoralis Muller 1784 (Oligochaeta). J. exp. mar. Biol. Ecol. 59: 231-241 
McCall, P. L. (1977). Community patterns and adaptive strategies of the infaunal benthos of Long Island Sound. J. mar. Res. 35: 221-266

Mendenhall, W. (1968). Introduction to linear models and the design and analysis of experiments. Duxbury Press, Belmont, California

Richter, W., Sarnthien, M. (1977). Molluscan colonization of different sediments on submerged platforms in the western Baltic Sea. In: Keegan, B. F., O'Ceidigh, P., Boaden, P. J. S. (ed.) Biology of benthic organisms. Pergamon Press, New York, p. 531-539

Sanders, H. L., Grassle, J. F., Hampson, G. R., Morse, L. S., Garner-Price, S., Jones, C. C. (1980). Anatomy of an oil spill: long-term effects from the grounding of the barge Florida off West Falmouth, Massachusetts. J. mar. Res. 38: $265-380$
Sokal, R. R., Rohlf, F. J. (1969). Biometry. W. H. Freedman and Company, San Francisco, California

Tenore, K. R. (1981). Organic nitrogen and caloric content of detritus. I. Utilization by the deposit-feeding polychaete Capitella capitata. Estuar. coast. mar. Sci. 12: 39-47

Thistle, D. (1981). Natural physical disturbances and communities of marine soft bottoms. Mar. Ecol. Prog. Ser. 6: 223-228

Woodin, S. A. (1976). Adult: larval interactions in dense infaunal assemblages: patterns of abundance. J. mar. Res. 34: $25-41$

Zajac, R. N., Whitlatch, R. B. (1982a). Responses of estuarine infauna to disturbance. I. Spatial and temporal variation of initial recolonization. Mar. Ecol. Prog. Ser. 10: 1-14

Zajac, R. N., Whitlatch, R. B. (1982b). Responses of estuarine infauna to disturbance. II. Spatial and temporal variation of succession. Mar. Ecol. Prog. Ser. 10: 15-27

This paper was presented by Professor K. R. Tenore; it was accepted for printing on April 16, 1984 